\title{
PROXIMATE AND ULTIMATE ANALYSIS OF FUEL PELLETS FROM OIL PALM RESIDUES
}

\author{
U. P. Onochie ${ }^{1}$, A. I. Obanor' ${ }^{2}$, S. A. Aliu ${ }^{3}$ and 0. O. Ighodaro ${ }^{4, *}$ \\ 1,2,3, National Centre For EnERgy and Envt. University of Benin, Benin City, Edo State. NiGERIA

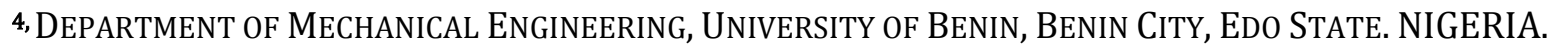 \\ E-mail addresses: ${ }^{1}$ onochieuche@yahoo.com, ${ }^{2}$ aiobanor@uniben.edu.ng, 3 sufianu.aliu@uniben.edu.ng, \\ 4 osaighodaro@gmail.com
}

\begin{abstract}
This study carried out an investigation on the proximate and ultimate analysis of fuel pellets from oil palm residues such as palm kernel shell, PKS, palm fibre, PF and empty fruit bunch, EFB using the ASTM standards. The results obtained were compared. The percentage moisture content of the pellets, PKS, PF and EFB were 9.68\%, 10.77\%, 12.07\% respectively. This is significantly lower than the percentage moisture content of the raw residues given as $10.23 \%, 11.10 \%$ and $15.01 \%$ respectively. High volatile matter content in the fuel pellets indicates that there would be ease of ignition during combustion. The results also show that the pellets have a lower ash content of $0.69 \%, 3.69 \%$ and $3.72 \%$ as against that of the raw residues, which is $3.24 \%, 7.90 \%$ and $4.48 \%$ respectively. There was really no significant reduction in emission of sulphur gases between the fuel pellets and the raw residues except for the Palm Fibre, PF, pellets and raw residues that varies. Essentially, from the general results obtained from the analysis, it can be deduced that pellets are more suitable for boilers in steam power plants.
\end{abstract}

Keywords: Oil Palm Residues, Fuel Pellets, Proximate Analysis, Ultimate Analysis

\section{INTRODUCTION}

The increase in the demand of renewable energy such as biomass is significantly growing worldwide [1] [2]. Biomass is used in various forms and as fuel for energy utilisation. Generally, biomass is generated in abundance in Nigeria and is normally used as fuel in its loose form. Pelletizing of this biomass resources into pellets is a way of ensuring a sustainable solid fuel for effective and efficient combustion purposes. The majority of pellets produced globally utilises wood chips as a feedstock [1]. However, due to realistic harvest yields and recovery rates, wood as a feedstock may not meet the growing demand for pellets [3], and alternative feed-stocks such as palm kernel shell, palm fibre and empty fruit bunch also generated in abundance will therefore be required to meet this growing demand. Biomass as a feedstock varies widely in its chemical composition [4 - 6]. The varying components include moisture content (MC), total carbon content (TCC), sulphur content (SC) and ash content (AC); variation is due to factors including varying harvest dates and methods, weather conditions, plant genetics and soil composition [7]. These proximate and ultimate values have an effect on quality parameters e.g. the HHV of the biomass pellets [5].
Fuel pellets produced under different conditions have been reported to have different handling characteristics [8]. These characteristics are also found to be strongly affected by the raw material properties. If pellets from biomass or agro-waste are to be used efficiently and rationally as fuel for combustion in boilers, they must be characterized to determine parameters such as the moisture content, calorific value, ash content, density, volatile matter, fixed carbon, carbon content, oxygen content, sulphur content among others. The result of these determinations indicates the positive and negative attributes of the pellets from agro waste and other biomass resources. Among the positive attributes of agro-waste pellets are low moisture content, high density, flame propagation, low ash content, low sulphur content, high amount of carbon, and substantial heating value. In [9], it was reported that moisture content is a very important property which affects the burning characteristics of biomass material. Volatile matter content has also been shown to influence the thermal behaviour of solid fuels [10]. The proximate and ultimate compositions of agro waste pellets vary from one type to another. Since pellets can be made from wide varieties of agro-residues, selection of the best pellets has to be made based on the analysis of its proximate and ultimate 
compositions. This will go a long way to ensuring judicious use of these wastes. In this study, fuel pellets made from oil palm residues such as palm kernel shell PKS, palm fibre PF, and empty fruit bunch EFB, were subjected to proximate and ultimate analysis in order to determine their suitability for combustion in boilers for power generation.

\section{METHODOLOGY}

Pellets were produced from oil palm residues i.e. Palm Kernel Shell, Palm Fibre and Empty Fruit Bunch, using waste paper as a binder. The ASTM standard D5373-02 of 2003 was adopted for the proximate analysis while an ASTM analytical method was used for the ultimate analysis as prescribed by [11].

\subsection{Determination of Proximate Analysis}

The proximate analysis is the physical properties of the fuel and it consist of the moisture content, ash content, volatile matter as well the fixed carbon. The formula used for determining the constituent of the proximate analysis is thus:

\subsubsection{Moisture content}

Procedure: Each sample of mass $10 \mathrm{~g}$ were measured and placed in the porcelain separately. The porcelain and its content were then oven dried at $110^{\circ} \mathrm{C}$ to a constant weight for 3 hours. The formula is given below:

$$
\% \mathrm{MC}=\frac{(\mathrm{g}-\chi)}{\mathrm{g}} \times 100
$$

In (1), $g$ is the Weight of sample, $\chi$ is the Weight of dry matter and $(g-\chi)$ is the Loss in weight

\subsubsection{Ash Content}

The muffle furnace was used to analyze the ash contenet of the pellets.

$$
\% \text { Ash }=\left(\frac{\chi}{g}\right) \times 100
$$

Here, $\mathrm{g}$ is the weight of sample and $\chi$ is the weight of ash

\subsubsection{Volatile Matter}

$$
\% \mathrm{~V} . \mathrm{M}=\left(\frac{\chi-\mathrm{y}}{\mathrm{g}}\right) \times 100
$$

Here, $g$ is the weight of sample, $\chi$ is the Weight of dry matter and $y$ is the Weight of residue

\subsubsection{Fixed Carbon}

$$
\% \mathrm{FC}=100-(V M+A s h+M C)
$$

Where, VM is the volatile matter, MC is the moisture content and Ash is the Ash content

\subsection{Determination of Ultimate Analysis}

The ultimate analysis is the chemical properties of the fuel and it consists of the carbon content, oxygen content, hydrogen content, nitrogen content and sulphur content. The formula used for determining the constituent of the ultimate analysis is according to[11]:

\subsubsection{Carbon content}

$\%$ Carbon $=\frac{(B-T) \times M \times 0.003 \times 100 \times 1.33)}{g}$

In (5), B is the Blank Titre, $\mathrm{T}$ is the Sample Titre, $\mathrm{M}$ is the molarity of the acid used and $g$ is the Weight of sample

\subsubsection{Nitogen content}

$$
\% \text { Nitrogen }=\frac{(\mathrm{T} \times \mathrm{M} \times 0.014 \times \mathrm{DF})}{\mathrm{g}} \times 100
$$

Here, $\mathrm{M}$ is the molarity of the acid used, $\mathrm{g}$ is the Weight of sample, $\mathrm{T}$ is the Titre value and DF is the Dillusion factor diluted

\subsubsection{Sulphur content}

$$
\% \text { Sulphur }=\frac{\chi \times 0.1373}{\mathrm{~g}} \times 100
$$

Here, $g$ is the weight of sample and $\chi$ is the weight of $\mathrm{BaSO}_{4}$

\subsubsection{Hydrogen content}

\subsubsection{Oxygen content}

$$
\% \text { Hydrogen }=\frac{\text { wt of } \mathrm{H} 20 \times 0.1119 \times 100}{\text { wt of pellet }}
$$

$$
\% \text { Oxygen }=100-(\mathrm{C}+\mathrm{H}+\mathrm{N}+\mathrm{S}+\% \text { Ash })
$$

\section{RESULTS}

\subsection{Results of Proximate Analysis of Fuel Pellets and Raw Residues}

The result from the proximate analysis of the fuel pellets and raw residues (PKS, PF and EFB) are shown in Table 1 and Table 2 respectively. The moisture content of a fuel has a great influence on the energy value and combustion performance of the fuel. From literature, good moisture content ranges between $8-12 \%$ and less. This is considered as key for a good and sustainable combustion.

Table 1: Proximate Analysis of Fuel Pellets

\begin{tabular}{lcccc}
\hline \multicolumn{1}{c}{ Fuel Pellets } & \% Moisture & \% Ash & \% Fixed Carbon & \% Volatile Matter \\
\hline Palm Kernel Shell, PKS & 9.68 & 0.69 & 5.53 & 84.10 \\
Palm Fibre, PF & 10.77 & 3.69 & 1.51 & 84.03 \\
Empty Fruit Bunch, EFB & 12.07 & 3.72 & 1.23 & 82.98 \\
\hline
\end{tabular}


Table 2: Proximate Analysis of Raw Residues

\begin{tabular}{lcccc}
\hline Raw Residues & \% Moisture & \% Ash & \% Fixed Carbon & \% Volatile Matter \\
\hline Palm Kernel Shell, PKS & 10.23 & 3.24 & 1.42 & 85.11 \\
Palm Fibre, PF & 11.10 & 7.90 & 1.01 & 80.08 \\
Empty Fruit Bunch, EFB & 15.01 & 4.48 & 0.98 & 79.58 \\
\hline
\end{tabular}

Thus, from the result of the moisture content analysis of the pellets, it shows that the pellets have a moisture content that ranges between $9-12 \%$ as shown in Table 1 . This means that the fuel pellets have good moisture content. This will influence the energy value and combustion performance of the pellets. In comparison, the result of the fuel pellets also shows that there is a significant reduction in the percentage moisture content as against that obtained from the raw residues which ranges between $10-15 \%$ and regarded as not quiet suitable. Essentially, it means that fuel pellets are more effective, efficient and sustainable than the raw residues when considered and used as an alternative fuel to fire boilers in steam power stations.

The amount of fixed carbon and volatile combustible matter directly contribute to the heating value. Table 1 shows higher volatile matter content in the fuel pellets and this indicates that there would be easy of ignition during combustion as against that of the raw residues with lower volatile matter as shown in Table 2. Fixed carbon acts as a main heat generator during burning. As expected, the amount of fixed carbon contained in the pellets is higher than that contained in the raw residues, which of course have a large influence on the calorific values. This means that the pellets would be more sustainable for power generation than the raw residues. Again, in Table 1 and 2, the results also show that the pellets have a significant lower ash content compared to the raw residues. This is due to the fact the pellets are in solid form and burns slowly and sustainably unlike the raw residues in loose form which burns faster and incomplete, thus forming a lot of ash. In boiler operations, high ash content value could be detrimental as it contributes to slagging of water tube surfaces in boilers. It also reduces handling and burning capacity, increases handling costs, affects combustion efficiency and boiler efficiency. Therefore, the values of the ash content obtained in the fuel pellets are considerably minimal when compared to higher values obtained in the raw residues. This means that the reduction in ash content of the pellets makes them more suitable for power generation.

\subsection{Results of Ultimate Analysis of Raw Oil Palm Residue}

The results from the ultimate analysis of the raw residues (PKS, PF and EFB) are shown in Table 3 and Table 4 respectively.

From Tables 3 and 4, there was really no significant reduction in emission of sulphur gases between the pellets and the raw residues except for the PF pellets and PF raw residues that vary. However, both fuels have good and considerable low sulphur contentas according toBureau of Energy Efficiency, normal sulphur content for fuels ranges from 0.5 to $0.8 \%$ normally. Corrosion is the main disadvantage of high sulphur content by sulphuric acid formed during and after combustion, and condensing in cool parts of the chimney, economiser and air pre heater. The percentage sulphur content as obtained in the results is considerably minimal for each of the fuels (pellets and raw residues). However, the with low sulphur content in the PF pellets, it is expected that there would be slow corrosion rate in the boiler if pellets are used.

Table 3: Ultimate Analysis of Fuel Pellets

\begin{tabular}{cccccc}
\hline Fuel Pellets & \% Carbon & \% Nitrogen & \% Sulphur & \% Hydrogen & \% Oxygen \\
\hline Palm Kernel Shell, PKS & 46.28 & 0.90 & 0.10 & 5.59 & 46.44 \\
Palm Fibre, PF & 39.90 & 2.01 & 0.12 & 5.40 & 48.88 \\
Empty Fruit Bunch, EFB & 42.91 & 0.45 & 0.10 & 5.27 & 47.55 \\
\hline
\end{tabular}

Table 4: Ultimate Analysis of Raw Residues

\begin{tabular}{cccccc}
\hline Raw Residues & \% Carbon & \% Nitrogen & \% Sulphur & \% Hydrogen & \% Oxygen \\
\hline Palm Kernel Shell, PKS & 47.88 & 0.94 & 0.10 & 5.15 & 42.69 \\
Palm Fibre, PF & 42.20 & 2.21 & 0.14 & 5.21 & 42.34 \\
Empty Fruit Empty, EFB & 43.89 & 0.52 & 0.10 & 5.33 & 54.32 \\
\hline
\end{tabular}




\section{CONCLUSION}

Proximate and ultimate analysis of pellets produced from raw residues of oil palm was carried out. Results obtained from the pellets and raw residues were compared. It was observed that there is a significant lower moisture and ash contents in the pellets than the raw residues. It was also observed that the sulphur content for PF pellets is lower than that from the raw residues. Essentially, the implication of the results means that pellets as fuel for combustion in boilers would be more suitable than the raw residues from oil palm for power generation. Again, another implication is that with the use of pellets for firing boilers, the maintenance cost of the boiler would be low.

\section{REFERENCES}

[1] Allison G, Morris C, Hodgson E, Jones J, Kubacki M, Barraclough T. Measurement of key compositional parameters in two species of energy grass by Fourier transform infrared spectroscopy. Bioresour Technol; 100:6428-33. 2009.

[2] Gil MV, Oulego P, Casal M. D, Pevida C, Pis J. J, Rubiera F. Mechanical durability and combustion characteristics of pellets from biomass blends. Bioresour Technol; 101:8859-67. 2010.

[3] Nolan A, McDonnell K, Devlin GJ, Carroll JP, Finnan J. Potential availability ofnon-woody biomass feedstock for pellet production within the Republic of Ireland. Int J Agri Biol Eng 2010;3:63-73. 2010:
[4] Obernberger I, Thek G. The Pellet Handbook - The Production and Thermal Utilisation of Pellets. London: Earthscan. 2010.

[5] Lewandowski I, Kicherer A. Combustion quality of biomass: practical relevance and experiments to modify the biomass quality of Miscanthus $\mathrm{x}$ giganteus. Eur J Agron ;6:163-77. 1997.

[6] Fagan C. C, Everard C. D, McDonnell K. Prediction of moisture, calorific value, ash and carbon content of two dedicated bioenergy crops using near-infrared spectroscopy. Bioresour Technol; 102:5200-6. 2011.

[7] Everard C. D, Fagan C C, McDonnell K. Visible-near infrared spectral sensing coupled with chemometric analysis as a method for on-line prediction of milled biomass composition pre-pelletising. $J$ Near Infrared Spectrosc, 20:361-9. 2012.

[8] Andrew Ndudi Efomah, Agidi Gbabo The Physical, Proximate and Ultimate Analysis of Rice Husk Briquettes Produced from a Vibratory Block Mould Briquetting Machine. IJISET - International Journal of Innovative Science, Engineering \& Technology, Vol. 2 Issue 5, May 2015.

[9] Yang, Y. B., Ryu, C., Khor, A., Yates, N. E., Sharifi, V. N., Swithenbank, J. Effect of fuel properties on biomass combustion. Fuel 84; 2116-2130. 2005.

[10] Loo, S. V., Koppejan, J. The Handbook of Biomass Combustion and Co-firing. Earthscan, London. 2008.

[11] Jenkins, B. M., Baxter, L. L., Miles, Jr., T. R, Miles, T. R. Combustion properties of biomass Fuel Process Technology.54:17-46. 2008. 